\title{
Generalidades de la seda y su proceso de teñido
}

\section{A short overview of silk and its dyeing process}

\author{
Laura González Echavarría ${ }^{1}$, Melissa Fontalvo Silva ${ }^{1}$, \\ Catalina Álvarez López ${ }^{2,3}$, Adriana Restrepo Osorio ${ }^{1,2}$ \\ ${ }^{1}$ Semillero de Investigación en Textiles SI Textil; Programa de Ingeniería Textil. \\ ${ }^{2}$ Grupo de Investigación sobre Nuevos Materiales, GINUMA. \\ ${ }^{3}$ Grupo de Investigaciones Agroindustriales, GRAIN. Programa de Ingeniería Agroindustrial. \\ Universidad Pontificia Bolivariana; Circular 1, No. 70-01, Medellín, Colombia. \\ adriana.restrepo@upb.edu.co
}

Recibido 9/02/14, aceptado 5/03/2014

\section{RESUMEN}

La seda es un filamento de origen animal producido por el gusano Bombyx mori. Esta fibra se caracteriza por su suavidad y brillo único, lo cual se atribuye a la forma triangular de su sección transversal. Además, tiene una alta resistencia a la tracción y una alta tenacidad, similar a la de algunas fibras sintéticas. En este trabajo se realizó una revisión bibliográfica de los procesos que requiere la seda para obtener un teñido homogéneo, partiendo desde los tratamientos previos de tintura hasta las pruebas de caracterización de solidez del color.

Palabras clave: Seda, Gusano Bombyx mori, Teñido, Colorantes, GOTS.

\section{ABSTRACT}

Silk is a filament of animal origin produced by the Bombyx mori silkworm. This fiber is characterized by its unique softness and gloss, which is attributed to the triangular shape of its cross section. It also has a high tensile strength and a high toughness, similar to some synthetic fibers. In this paper an literature review of the processes required for a homogeneous dyeing in silk was performed, starting from the dyeing pretreatments up to the color fastness characterization tests.

Keywords: Silk, Silkworm Bombyx mori, Dyeing process, Dyes, GOTS.

\section{INTRODUCCIÓN}

La seda es una fibra natural de origen animal producida por algunos insectos, entre los cuales se encuentra el gusano de seda Bombyx mori. Este gusano se alimenta de la hoja de morera y forma un capullo que puede devanarse para obtener filamentos continuos. A partir de varios filamentos reunidos y torsionados, se obtienen hilos, los cuales pueden emplearse en la obtención de diversos productos textiles [1].

Los orígenes del uso de la seda como materia prima textil se sitúan en China, donde su producción comenzó con la cría del gusano hace más de 5000 años [2]. Luego se introdujo en India, que actualmente es el segundo mayor productor y consumidor de seda del mundo. Posteriormente se expande en todo el continente Asiático, para después establecerse en Europa. La sericultura llega a América Latina en la época de la colonia de manera intermitente, hasta que en las décadas de 1970 y 1980 se consolidan la mayoría de los proyectos productivos que existen en la actualidad $[3,4]$.

En Colombia, alrededor del año 1980, se comienzan iniciativas formales de invertir en la sericultura, convirtiéndose en una de las opciones de diversificación para los caficultores nacionales [5]. Por esta razón, la actividad serícola en el país se ha concentrado en los departamentos cafeteros del país como: Caldas, Risaralda, Quindío, Cauca y Valle del Cauca [4, 6]. En la actualidad pueden encontrarse organizaciones que agrupan a los sericultores, como es el caso de la Corporación para el Desarrollo de la Sericultura del CaucaCORSEDA. 
El proceso de transformación textil de la seda se efectúa en diferentes etapas. Se inicia con el devanado, posteriormente el hilado, la tejeduría y el teñido. Luego es posible confeccionar prendas para su uso en vestuario, en el hogar o en otras aplicaciones. Tradicionalmente, el teñido de la seda se ha realizado con colorantes naturales, tendencia que sigue siendo empleada hoy en día por algunos sericultores. No obstante, con el paso de los años el uso de estos colorantes ha disminuido, debido entre otras razones, a la aparición de colorantes sintéticos. Éstos últimos proporcionan mejores resultados en reproducibilidad de tonos y propiedades de solideces, comparándolos con los colorantes naturales. Sin embargo, el uso de colorantes sintéticos incrementa la contaminación y la toxicidad de las aguas residuales de los procesos tintóreos.

Frente a este panorama y siguiendo las tendencias mundiales, que en los últimos años procuran la producción de textiles con un menor impacto ambiental, aparece la denominación de productos orgánicos y las certificaciones que los regulan, entre las cuales está la norma GOTS, cuya publicación se realizó a finales del año 2006 [7]. El objetivo de la normativa GOTS es definir los requerimientos que aseguran la condición orgánica de los productos textiles. Esto incluye la obtención de la materia prima y su transformación responsable con el medio ambiente, es decir, que los productos empleados o procesos realizados a la misma, no deben contaminar las vertientes, ni poner en riesgo la salud de las personas que los realizan. También se tienen en cuenta los aspectos sociales, por lo que el trabajo no debe ser forzado, no debe existir mano de obra infantil, las condiciones laborales deben ser seguras e higiénicas, debe existir una remuneración acorde con el salario mínimo legal, no deben excederse los horarios laborales y se debe garantizar el empleo regular. Además, la norma incluye aspectos sobre el correcto etiquetado a fin de que el producto final ofrezca al consumidor información sobre el cumplimiento de los requisitos antes mencionados [8].

Ese tipo de certificaciones es relevante para pequeños productores de seda, como es el caso de los asociados a CORSEDA, puesto que les permite elaborar productos de mayor valor agregado, que pueden ser comercializados en mercados especializados, y en cuyo proceso productivo se genera un menor impacto ambiental. Considerando lo anterior, y dado que existe en el país una actividad serícola consolidada cuyos productos se orientan en su mayoría a mercados internacionales orgánicos y certificados GOTS; en este artículo se hace un breve recorrido por los aspectos básicos de la seda, su proceso de teñido con colorantes naturales, sintéticos y certificados por la norma GOTS, así como sobre las pruebas de calidad que la normativa orgánica incluye. Esto como un aporte al fundamento básico para procesos experimentales relacionados con estos tópicos.

\section{GENERALIDADES}

\subsection{Composición química de la seda}

La fibra de seda se compone en un $97 \%$ de proteínas y un $3 \%$ de otros componentes como: ceras, carbohidratos, pigmentos y compuestos inorgánicos. Las principales proteínas en la fibra de seda son aproximadamente $75 \%$ fibroína $\left(\mathrm{C}_{15} \mathrm{H}_{23} \mathrm{~N}_{5} \mathrm{O}_{6}\right)$ y $25 \%$ sericina $\left(\mathrm{C}_{15} \mathrm{H}_{25} \mathrm{~N}_{5} \mathrm{O}_{8}\right)[9,10]$. La fibroína y la sericina están a su vez compuestas por diversos aminoácidos tal como se indica en la tabla 1.

Tabla 1. Composición típica de aminoácidos presentes en la fibroína y la sericina expresado en porcentaje (\%).

Table 1. Typical composition of amino acids present in fibroin and sericin as a percentage (\%).

\begin{tabular}{|c|c|c|}
\hline Aminoácidos & Fibroína & Sericina \\
\hline Glicina & 44,5 & 14,7 \\
\hline Alanina & 29,3 & 4,3 \\
\hline Serina & 12,1 & 37,3 \\
\hline Tirosina & 5,2 & 2,6 \\
\hline Valina & 2,2 & 3,6 \\
\hline Ácido aspartico & 1,6 & 14,8 \\
\hline Ácido glutamico & 1 & 3,4 \\
\hline Treonina & 0,9 & 8,7 \\
\hline Isoleucina & 0,7 & 0,7 \\
\hline Fenilalanina & 0,6 & 0,3 \\
\hline Leucina & 0,5 & 1,4 \\
\hline Arginina & 0,5 & 3,6 \\
\hline Lisina & 0,3 & 2,4 \\
\hline Prolina & 0,3 & 0,7 \\
\hline Histidina & 0,2 & 1,2 \\
\hline Metionina & 0,1 & - \\
\hline Triptófano & 0,2 & - \\
\hline Cistina & 0,04 & 0,1 \\
\hline
\end{tabular}

Fuente: Adaptado de [11]

La fibroína es una estructura lineal altamente orientada y cristalina, es la proteína estructural de la seda. La sericina, por su parte, es un pegamento proteico parcialmente hidrosoluble y de estructura globular, que sirve para unir las fibras entre sí. Cada gusano excreta dos filamentos de fibroína simultáneamente, que unidos por la sericina constituyen la fibra (ver figuras 1 y 2 ) y es empleada para formar el capullo $[9,10]$. 
Figura 1. Esquema de la fibra de seda [9].

Figure 1. Scheme of silk fiber [9].

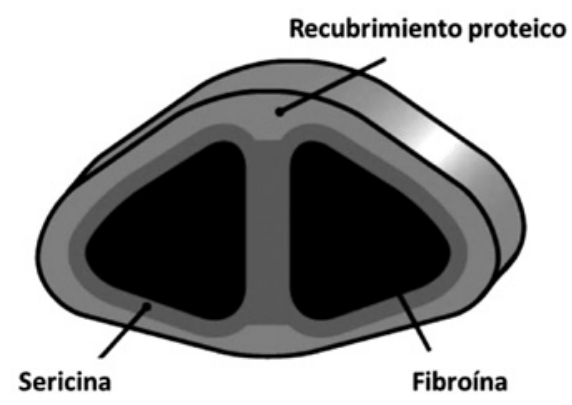

Figura 2. Micrografía SEM de la fibra de seda [12]. Figure 2. SEM micrograph of silk fiber [12].

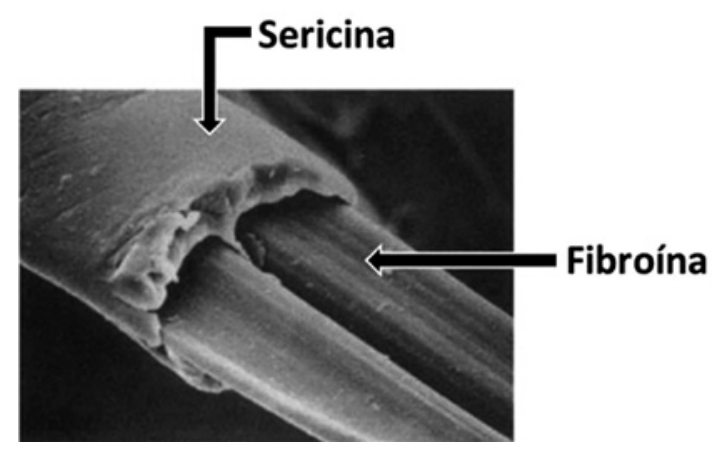

\subsection{Propiedades de la seda}

Entre las fibras textiles naturales la seda se destaca gracias a sus particulares propiedades. Por ejemplo su higroscopía, es decir, en condiciones estándares tiene un de regain cerca al $11 \%$ y es capaz de absorber hasta el 30\% de su peso de agua sin generar sensación de humedad, lo que la hace confortable al contacto con la piel [13]. Sus propiedades tensiles específicas son superiores a la mayoría de las fibras naturales y comparables con fibras sintéticas de alto desempeño como el Kevlar® [14], con una tenacidad de 5 g/denier y una elongación de $1725 \%$. La sección transversal de la seda es triangular con esquinas redondeadas (ver figura 1), esto le proporciona una excelente capacidad de reflexión de la luz, razón por la cual es una fibra lustrosa. Cada filamento mide de 5 a $10 \mu \mathrm{m}$ de diámetro aparente y puede alcanzar una longitud de hasta $1600 \mathrm{~m}$, por lo que se le considera una microfibra natural [13].

La seda es mala conductora de electricidad y por lo tanto susceptible a almacenar electricidad estática. Tiene una baja conductividad térmica, su temperatura de transición vítrea es $\sim 175{ }^{\circ} \mathrm{C}$ y su degradación térmica se encuentra cerca de $250^{\circ} \mathrm{C}$, por lo que tolera procesos con temperaturas de hasta $150{ }^{\circ} \mathrm{C}$ [15]. Es resistente a la mayoría de los ácidos minerales a excepción del ácido sulfúrico, mientras que es sensible a medios alcalinos $(\mathrm{pH}>9)$. Es soluble en disolventes como bromuro de litio acuoso, ácidos fosfóricos y soluciones de cupramonio, y no es resistente a los agentes oxidantes fuertes como el hipoclorito de sodio y el cloro [16].

La seda contiene dos grupos reactivos principales, los amino $\left(-\mathrm{NH}_{2}\right)$ y los carboxílicos (-COOH). Es una fibra anfótera, con un punto isoeléctrico cerca a $\mathrm{pH} \sim 5$ [17]. En esta condición su carga es neutra y por debajo de este $\mathrm{pH}$ presenta un carácter catiónico [18], por lo cual existen metodologías adecuadas para teñirla con diferentes colorantes en medios ácidos y alcalinos.

\section{TEÑIDO DE LA SEDA}

Para el proceso de tintura como para otros acabados químicos, se requiere realizar la preparación de la fibra o desengomado, con miras a remover la sericina, las grasas y los demás contaminantes naturales o adquiridos durante el proceso de obtención de la seda. Este proceso y el de tintura se describen a continuación.

\subsection{Desengomado}

El desengomado es un proceso de preparación que se realiza para eliminar la sericina presente en la fibra. Industrialmente es posible desengomar la seda en madejas, hilos o tejidos. La remoción total o parcial de la sericina depende del uso final de las fibras, por ejemplo, para colores claros y brillantes se requiere una exhaustiva remoción de la sericina [19], mientras que para la elaboración de tejidos livianos como los tipo organza, es recomendable mantener una pequeña cantidad de sericina, la cual aporta resistencia a los hilos durante la tejeduría [13].

Tradicionalmente el proceso de desengomado se lleva a cabo con jabón neutro basado en aceites vegetales, como el jabón de Marsella [13], o en Colombia con jabón de coco [20]. La solución jabonosa se basifica ligeramente con bicarbonato de sodio y se lleva junto con la seda a ebullición durante un tiempo que oscila entre $30 \mathrm{~min}$ y $1 \mathrm{~h}$.

Diversos métodos de desengomado son objeto de estudio y aplicación, con miras a preservar las características de la seda y de la sericina, o a causar un menor impacto en el medio ambiente, entre otros. Se han estudiado métodos de desengomado con agua caliente [21], con la asistencia de autoclaves o de microondas [22]. También se encuentran reportes de procesos de desemgonado con enzimas tipo proteasas [23, 24] y basados en medios ácidos [25, 26]. En los proceso de desengomado de la seda, las variables a tener en cuenta son: la concentración del jabón, el ácido, el álcali o la enzima que se emplea; la temperatura, el tiempo y el $\mathrm{pH}$ del baño [27, 28]. 


\subsection{Tintura}

El teñido de la seda a nivel industrial suele realizarse en madeja, pero es posible teñir las telas o prendas terminadas, e incluso los capullos antes de los procesos de transformación. En el proceso de tintura, adicional a la correcta preparación de la fibra, son relevantes las siguientes variables:

Dureza del agua: Se refiere al conjunto de cationes, especialmente de $\mathrm{Ca}^{2+} \mathrm{y} \mathrm{Mg}^{2+}$, presentes en el agua que será empleada para el teñido y otros procesos textiles. Es importante conocer y adecuar la dureza del agua de moderados a bajos, puesto que valores altos de dureza puede interferir en el proceso de tintura disminuyendo la interacción colorantefibra [29].

Relación de baño: Es la relación que existe entre la cantidad de material a teñir y el baño utilizado. Tiene influencia directa en la absorción y adsorción del colorante en la fibra. Se emplean típicamente relaciones de baño de 1:40 o 1:30, dependiendo del tipo de maquinaria o sistema de teñido disponible [29].

Temperatura: Esta variable es de gran importancia en la fijación del colorante en la fibra. En el proceso de tintura de la seda la temperatura ideal oscila entre $85-90{ }^{\circ} \mathrm{C}$ [30].

Tiempo: Igual que la temperatura, esta variable 85-90 está relacionada directamente con la fijación del colorante en la fibra. En el proceso de la seda el tiempo ideal oscila entre 60-120 $\mathrm{min}[30]$.

pH (potencial de hidrógeno): Se usa para determinar la alcalinidad o acidez de una solución. La condición ideal de $\mathrm{pH}$ se define de acuerdo al tipo de colorante empleado, siendo los de más frecuente uso los colorantes tipo ácido. Los valores adecuados para la tintura de la seda oscilan entre 45 [31]. En estas condiciones los grupos aminas son protonados $\left(-\mathrm{NH}_{3}^{+}\right)$y de esta forma son más reactivos con los grupos funcionales de los colorantes.

Auxiliares: Los productos auxiliares aseguran la estabilidad ya sea del sustrato textil o del colorante durante el proceso de tintura. En el caso de la seda se usan auxiliares tales como humectantes; fijadores; acidulantes como ácido acético o cítrico; mordientes y otros [32].

Colorantes: Son las sustancias químicas que tienen la capacidad de absorber y reflejar ciertas longitudes de onda del espectro de luz. En la tintura de la seda es posible utilizar una amplia gama de colorantes con buenos resultados. Se emplean colorantes naturales, de origen vegetal y animal; colorantes sintéticos: ácidos, reactivos, directos y dispersos, estos dos últimos en menor proporción.

\section{COLORANTES PARA LA TINTURA DE LA SEDA}

Los colorantes para la tintura de la seda independiente de su origen, deben tener la capacidad de penetrar en la fibra y fijarse adecuadamente en ésta. Actualmente, adicional a los requerimientos de calidad, se busca que los procesos de tintura generen un menor impacto en el medio ambiente, razón por la cual existe un creciente interés industrial e investigativo por los colorantes orgánicos y los certificados por normas de producción orgánica como la GOTS.

A continuación, se presentan algunos aspectos relevantes de los distintos tipos de colorantes antes mencionados.

\subsection{Colorantes naturales}

Los colorantes naturales se definen como aquellos productos de origen natural, que una vez aislados son capaces de impartir color a un sustrato. En el mundo textil los colorantes naturales son de especial interés para su uso en fibras de origen natural, en pro de obtener un producto final no tóxico y amigable con el medio ambiente [17, 33]. Muchas firmas comerciales de colorantes sintéticos han desarrollado en los últimos años, colorantes naturales para textiles y los comercializan a gran escala [34].

Los principales desarrollos de colorantes naturales para la tintura de la seda a escala industrial y artesanal, se centran en los de origen vegetal, dada su gran disponibilidad. Para esto se aprovechan hojas, cortezas, raíces [31, 35], e incluso residuos de los procesos productivos agroindustriales [31, $36,37]$. También se encuentran reportes del empleo de insectos como fuente para la obtención de colorantes para la seda, especialmente la cochinilla (Dactylopiuscoccus) [31, 38].

En Colombia se emplean algunos colorantes naturales provenientes de plantas para teñir la seda a nivel artesanal. Se obtienen de acuerdo a la disponibilidad de especies en la zona en la que se realice esta actividad. Por ejemplo, en el Cauca es común el uso de plantas como el nacedero (Trichanthera gigantea), el nogal (Juglans regia), el guayacán (Fabeburacrhysantha), residuos de café, e incluso las hojas de la morera (Morusalba) que es el alimento de los gusanos de seda [20].

Una de las debilidades de los colorantes naturales comparados con los sintéticos es que pueden presentar bajas solideces. Para mejorar su desempeño en el uso final, se hace indispensable el empleo de mordientes, los cuales promueven la afinidad del colorante y la fibra, mejorando la fijación [17]. En general, los mordientes mejoran la calidad del teñido, y al variar el tipo de producto empleado para este fin se logran colores y tonos diversos a partir de un mismo colorante natural [39]. Esto es aprovechado por los artesanos para obtener una amplia gama de colores. 
A nivel mundial y en Colombia, se emplean para el proceso de mordentado sales metálicas como: el sulfato de cobre, el dicromato de potasio, el sulfato de hierro, el sulfato ferroso y el alumbre [17, 20,31]. Si bien éstos mejoran la calidad de la tintura, son en general contaminantes ambientales, lo que desvirtúa el aspecto natural de los colorantes. Por lo anterior, se buscan opciones para reemplazar especialmente los que contienen metales pesados. Se encuentran reportes del uso alternativo de mordientes provenientes de fuentes naturales como: hongos [40] o plantas [41], así como el uso de algunos ácidos orgánicos [8], entre otros.

El proceso de mordentado de la seda puede llevarse a cabo antes (premordentado), simultáneamente (mordentado) o posterior al proceso de teñido (postmordentado) [17]. Algunos estudios revelan que existe una tendencia en mejorar la retención del color al realizar el proceso de mordentado simultáneo a la tintura [40]. En la figura 3 se esquematiza un procedimiento general para el teñido de seda con colorantes naturales con mordentado.

Figura 3. Curva de teñido de la seda con colorantes naturales [31].

Figure 3. Silk dyeing curve with natural dyes [31].

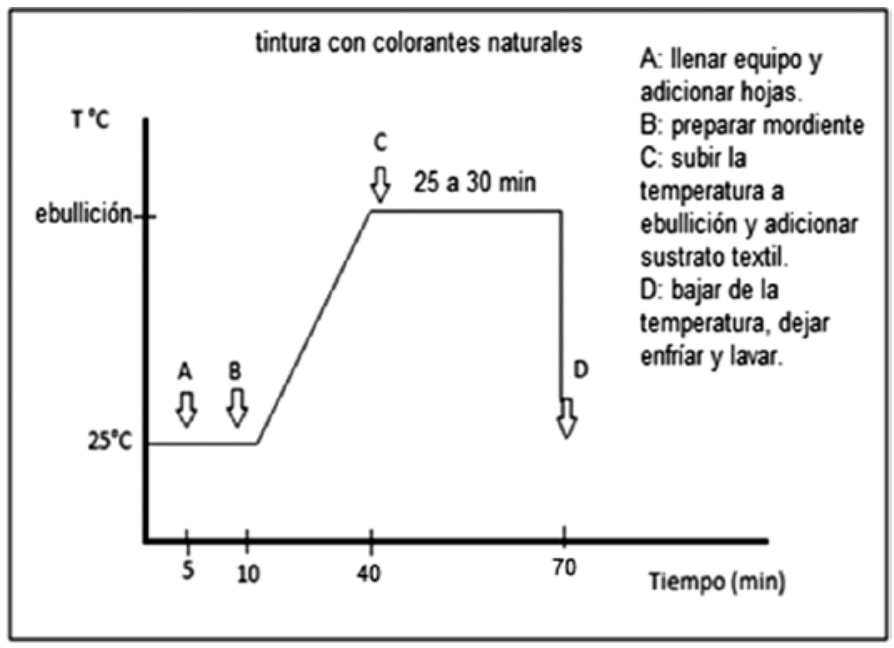

\subsection{Colorantes sintéticos}

Los colorantes sintéticos son desarrollados de acuerdo a las características de la fibra a teñir y muchos de ellos provienen de fuentes petroquímicas. A nivel industrial, los colorantes sintéticos tipo ácidos y reactivos son los más empleados en los procesos tintóreos de la seda, dada su afinidad por la fibra, reproducibilidad y altas solideces. A continuación se describen ambos tipos de colorantes.

\subsubsection{Colorantes ácidos}

Estos colorantes son solubles en agua, se clasifican de acuerdo a su comportamiento tintóreo, el $\mathrm{pH}$ de teñido, la capacidad de migración y su solidez [11]. Se usan para teñir sustratos en medios ácidos, se caracterizan por tener en su estructura al menos un grupo sulfonato $\left(\mathrm{SO}_{3}{ }^{-}\right)$ asociado al sodio $\left(\mathrm{Na}^{+}\right)$, lo que les permite solubilizarse en los baños acuosos de tintura y reaccionar con las fibras por medio de interacciones iónicas, esto gracias a que fibras como la lana, la seda o las poliamidas, en condiciones ácidas adquieren cargas positivas [42]. La seda presenta grupos catiónicos amonio y grupos aniónicos carboxilatos, que reaccionan con los grupos funcionales de estos colorantes ácidos mediante fuerzas polares, formando sales.

\subsubsection{Colorantes reactivos}

Los colorantes reactivos son los más usados en la industria textil debido a su facilidad de aplicación, su amplia gama de colores y su relativo bajo costo. Se fijan al tejido mediante la formación de enlaces covalentes, haciéndolos resistentes al lavado y otorgando buenas solideces [19]. Estos colorantes se conocen como compuestos químicos coloreados, son de carácter aniónico y su molécula se compone de una parte colorante y la otra reactiva [41]. Su aplicación está orientada principalmente a las fibras celulósicas, sin embargo también son empleados en fibras proteicas como la seda pero con menor afinidad tintórea [43]. Para resolver este inconveniente se requiere la adición de gran cantidad de sales, como cloruro o sulfato de sodio, o bien modificaciones químicas de la seda con grupos catiónicos. Ambas opciones representan costos adicionales y efectos adversos para el medio ambiente [44].

\subsection{Colorantes certificados por la norma GOTS}

Otra opción disponible comercialmente son los colorantes con certificación orgánica, por ejemplo los de la normativa GOTS. Éstos pueden ser de origen natural, sintético o una mezcla de ambos, se caracterizan por ser biodegradables y disminuir el impacto al medio ambiente, gracias a que son producidos con mínimo consumo de energía y agua [7]. Diversas casas productoras a nivel mundial como DyS$\operatorname{tar}{ }^{\circledR}$, Clariant y HUNSTMAN poseen este tipo de colorantes, que pueden emplearse en la tintura de la seda. En Colombia, la casa HUNTSMAN ha comenzado la distribución de colorantes ácidos certificados GOTS para su uso en seda, lana y poliamidas, bajo las marcas comerciales Erionyl ${ }^{\circ}$ y Tectilon ${ }^{\circledR}$.

Los colorantes Erionyl ${ }^{\circledR}$ y Tectilon ${ }^{\circledR}$ están compuestos por grupos azoicos $(\mathrm{N}=\mathrm{N})$ y antraquinónicos $(\mathrm{C}=\mathrm{O})$, los cuales se caracterizan por generar tonos y matices brillantes, alto agotamiento, buena igualación y una fácil reproducibilidad del color. Los colorantes Tectilon ${ }^{\circledR}$, a diferencia de los Erionyl®, presentan una baja solidez en húmedo y alta resistencia de solidez a la luz, haciéndolos aptos para el teñido de materiales como alfombras y tapicerías [45]. 


\section{PRUEBAS DE CALIDAD}

Una propiedad a estudiar en los textiles después del teñido es la solidez del color, ésta establece la resistencia que presenta el sustrato teñido, a cambiar su color o perder la intensidad luego de ser sometida a agentes externos. Las pruebas para determinarla se realizan a nivel de laboratorio, simulando condiciones reales de uso donde se combinan el efecto de la temperatura, la humedad, la acción del sol y otros factores [46].

Existen diferentes normativas de solidez del color en textiles elaboradas por diferentes organismos reguladores como: American Association of Textile Chemists and ColoristsAATCC, International Organization for StandardizationISO, American Society for Testing and MaterialsASTM, entre otras. En Colombia se trabajan las Normas Técnicas ColombianasNTC del Instituto Colombiano de Normas Técnicas y CertificaciónICONTEC. Las normativas pretenden establecer condiciones estándares de calidad y criterios de negociación.

Tabla 2. Parámetros técnicos de calidad exigidos por la normativa GOTS.

Table 2. Quality technical parameters demanded by GOTS standard.

\begin{tabular}{|c|c|c|}
\hline Parámetro & Criterio & $\begin{array}{l}\text { Método de } \\
\text { análisis }\end{array}$ \\
\hline $\begin{array}{l}\text { Solidez al frote seco para } \\
\text { mezclas de fibras }\end{array}$ & $\begin{array}{c}3-4 \\
3\end{array}$ & ISO $105 \times 12$ \\
\hline Solidez al frote húmedo & 2 & ISO $105 \times 12$ \\
\hline $\begin{array}{l}\text { Solidez al sudor, alcalino } \\
\text { y ácido para mezclas de } \\
\text { fibras }\end{array}$ & $\begin{array}{c}3-4 \\
3\end{array}$ & ISO 105 E04 \\
\hline Solidez a la luz & $3-4$ & ISO 105 B02 \\
\hline $\begin{array}{l}\text { Valores de reducción luego } \\
\text { del lavado a } 40^{\circ} \mathrm{C} \text { resp. y } \\
30^{\circ} \mathrm{C} \text { para fibra animal y } \\
\text { mezclas. Este criterio sólo } \\
\text { tiene validez para indu- } \\
\text { mentaria }\end{array}$ & & ISO 6330 \\
\hline $\begin{array}{l}\text { Tejidos de punto / lencería: } \\
\text { Tejido plano: }\end{array}$ & $\begin{array}{l}\text { máx. } 8 \% \\
\text { máx. } 3 \%\end{array}$ & \\
\hline Solidez a la saliva & $\begin{array}{l}\text { "FAST" para } \\
\text { ropa para be- } \\
\text { bés y niños }\end{array}$ & LMBG B 82.10-1 \\
\hline Solidez al lavado a $60^{\circ} \mathrm{C}$ & $3-4$ & $\begin{array}{c}\text { ISO } 105 \text { C06 } \\
\text { C1M }\end{array}$ \\
\hline $\begin{array}{l}\text { Solidez al lavado para } \\
\text { fibras animales y mezclas } \\
\text { a } 30^{\circ} \mathrm{C}\end{array}$ & $3-4$ & $\begin{array}{c}\text { ISO } 105 \text { C06 } \\
\text { A1S sin el uso } \\
\text { de bolas de ace- } \\
\text { ro; análogo con } \\
\text { reducción de la } \\
\text { temperatura de } \\
\text { lavado }\end{array}$ \\
\hline
\end{tabular}

Fuente: Tomado de [7].
En particular, la normativa GOTS establece cuáles son las pruebas de solidez del color que deben realizarse a los textiles que aspiren ser certificados, así como los valores que dichas pruebas deben alcanzar. A tales pruebas se les denomina parámetros técnicos de calidad y se listan en la tabla 2 [7].

Una vez realizadas las pruebas se compara la variación del color antes y después de realizar los procesos de evaluación de la solidez, tal como establece cada norma. Para la calificación de dicha variación se emplean escalas de grises, de cambio de color y de manchado, estas incluyen tonos de grises con que van de 1 a 5 , donde 5 indica que no hubo ninguna transferencia o cambio de color, y uno todo lo contrario [47]. Para la solidez a la luz se emplea una escala de azules que va de 1 a 7 , la cual se evalúa de manera análoga a la anterior.

Estos ensayos, normas y criterios de calificación, son similares a los reportados en la bibliografía por los investigadores que evalúan los procesos de tintura de la seda [35, 36, 43] y otras fibras proteicas [32], [34], también se aproximan a los criterios de negociación típicos de este tipo de textiles.

\section{CONCLUSIONES}

- La seda es una fibra natural proteica que se produce a pequeña escala en Colombia y cuyos productos estás orientados a mercados especializados, entre los que se encuentran los orgánicos y los certificados GOTS. Para la producción de textiles de seda, se realizan diversos procesos de transformación, uno de los cuales es el teñido, este imparte propiedades estéticas de color al producto. Para obtener un proceso uniforme de tintura son varios los requisitos a tener en cuenta, por ejemplo el desengomado, con el que se busca la remoción de la sericina y otras impurezas; también es preciso controlar las variables propias del teñido como la relación del baño, la dureza del agua, la temperatura, el tiempo, el pH y la concentración del colorante; de tal manera que se garanticen las condiciones óptimas del proceso.

- Para el teñido de la seda pueden empelarse una gran variedad de colorantes, naturales o sintéticos, los cuales a su vez pueden ser ácidos o reactivos. Es recomendable el uso de colorantes ácidos, dado que son los que mayor afinidad presentan por la seda. Existen además colorantes certificados por la norma GOTS que permiten obtener productos de buena calidad, disminuyendo la contaminación, e igualmente presentan afinidad por la seda. Una vez se realiza el teñido, y con miras a cumplir las normativas vigentes, es necesario realizar ensayos que garanticen el buen desempeño del producto final. Las pruebas de calidad más relevantes para el teñido son las de solideces del color, las cuales son evaluadas por medio de escala de grises, estableciendo los valores mínimos a cumplir. 
Con lo presentado en esta revisión se hace un recorrido por aspectos relevantes de la seda y su proceso de teñido, de cara a los procesos que hoy día se dan en el país y los nichos de comercialización que estos productos textiles tienen en el mundo.

\section{AGRADECIMIENTOS}

Los autores expresan su agradecimiento a la Corporación para el Desarrollo de la Sericultura del CaucaCORSEDA y al Instituto Nacional de Tecnología IndustrialINTI de Argentina, por su colaboración y apoyo en el desarrollo de este proyecto. A la UPB, al Semillero de Investigación en Textiles SI Textil y al CIDI por financiar parte de los recursos requeridos para el desarrollo de este trabajo a través del proyecto: "Aplicaciones textiles de la seda y sus subproductos", radicado: 020B-02/13-S79.

\section{REFERENCIAS}

[1] S. Burkinshaw and M. Paraskevas, "The dyeing of silk Part 1: Low temperature application of solubilised sulphur dyes using sodium thioglycolate," Dyes and pigments, 87, 225-233, 2010.

[2] C. Canales, Guías de mejoras técnicas disponibles en España del sector textil, Madrid: Centro de Publicaciones. Secretaria General Técnica. Ministerio de Medio Ambiente, 2004.

[3] A. C. Toro and C. Londoño Giraldo, Estudio de la estabilidad térmica del aceite de crisálida del gusano Bombix Mori Linn, Pereira: Trabajo de Grado, Universidad Tecnológica de Pereira, Colombia, 2007.

[4] C. M. Vietes, C. P. Bsso and H. Zunini, Aporte a la comprensión de la situación de la Sericicultura en la Argentina y en Latinoamérica, INTI-Imprenta, 2010.

[5] M. Calle, "Blog de la Institución Educativa San Antonio de Padua de Timbio, Cauca," 2007. [Online]. Available: http://timbio.blogspot.com/2007/05/la-historia-de-la-sedaen-timbio-y.html. [Accessed 21 agosto 2012].

[6] C. A. Cifuentes and K. W. Sohn, Manual técnico de la sericultura, cultivo de la morera y cria del gusano de seda en el trópico, Risaralda: Fondo Editorial de Risaralda, 1998.

[7] Global Organic Textile Standard, "Global Organic Textile Standard," [Online]. Available: http://www.globalstandard.org/. [Accessed 27 julio 2012].

[8] P. Kongkachuichay, S. Aroonsiri and C. Nontalee, "Thermodynamics of adsorption of laccaic acid on silk," Dyes and Pigments, 53, 179-185, 2002.
[9] J. Hardy, L. Römer and L. Scheibel, "Polymeric materials based on silk proteins," Polymer, 49, 4309-4327, 2008.

[10] M. Elices, J. Rigueiro, G. Plaza and G. Guinea, “Usos médicos de la seda," Investigación y ciencia, 419, 28-35, 2011.

[11] M. Mondal, K. Trivedy and S. Nirmal Kumar, "The silk proteins, sericin and fibroin in silkworm, Bombyx mori Linn.," Caspian Journal of Environmental Sciences, 5, 63-76, 2007.

[12] “DermaSilk®," [Online]. Available: dermasilk.com. au. [Accessed 14 noviembre 2012].

[13] R. Currie, "Silk," in Silk, Mohair, Cashmere and other Luxury Fibres, Cornwall, Woodhead Publishing Ltd and CRC Press LLC, 2001, pp. 1-67.

[14] M. Kinahan, E. Filippidi, S. Köster, X. Hu, H. Evans and T. Pfo, "Tunable Silk: Using Microfluidics to Fabricate Silk Fibers with Controllable Properties," Biomacromolecules, 12, 1504-1511, 2011.

[15] A. Matsumoto, H. Kim, I. Tsai, X. Wang, P. Cebe and D. L. Kaplan, "Silk," in Handbook of Fiber Chemistry, vol. Chapter 6, Boca Raton, CRC Press and Taylor \& Francis Group, 2007, pp. 383-404.

[16] H. Needles, "Protein Fibers," in Textile Fibers, Dyes, Finishes and Process. A Concise Guide, New Jersey, Noyes Publications, 1986, pp. 58-68.

[17] S. Ashiskumar and A. Konar, "Dyeing of Textiles with Natural Dyes: Natural dyes," in Natural Dyes, India: InTech, 2011, pp. 29-56.

[18] P. Bellini, F. Bonetti, E. Franzetti, G. Rosace and S. Vago, Reference Books of Textile Technology. Finishing, Milano: ACIMIT Foundation, 2002.

[19] J. Riva, M. Prieto and M. Neznakomova, “Influencia del tipo de desgomado en el comportamiento tintóreo de la seda," BOLETíN INTEXTER (U.P.C.), 119, 35-42, 2001.

[20] Artesanías de Colombia S.A. - CENDAR, "Artesanías de Colombia," [Online]. Available: http://www.artesaniasdecolombia.com.co. [Accessed Septiembre 2008].

[21] O. Hanjin, J. Lee, M. Kim, I. C. Um and K. Lee, "Refining hot-water extracted silk sericin by ethanol-induced precipitation," International Journal of Biological Macromolecules, 48, 32-37, 2011.

[22] N. Mohammad, F. Moghimi, M. Arami and F. Mazaheri, "Silk Degumming using microwave irradiation as an 
environmentally friendly surface modification method," Fibers and Polymers, 11, 234-240, 2010.

[23] G. Freddi, G. Allera and G. Candiani, "Degumming of silk fabrics with tartaric acid," Journal of the Society of Dyers and Colourists, 112, 191-195, 2008.

[24] V. Rinsey and S. Karpagam, "Degumming of silk using protease enzyme from bacillusspecies," InternationalJournal of Science and Nature, 3, 51-59, 2012.

[25] M. Nakpathom, B. Somboon and N. Narumol, "Papain enzymatic degumming of Thai Bombyx mori silk fibers," Journal of Microscopy Society of Thailand, 23, 142-146, 2009.

[26] M. Khan, M. Tsukada, Y. Gotoh, H. Morikawa and G. Freddi, "Physical properties and dyeability of silk fibers degummed with citric acid," Bioresource Technology, 21(101), 8439-8445, 2010.

[27] M. Gautam, B. Salil, M. Prabal and M. Moon, "A review on chemical processing of silk," Colourage, 56(2), 48-52, 2009.

[28] V. Krishnaveni, "Study on effect of proteolytic enzyme degumming on dyeing of silk," Colourage, 57(8), 61-73, 2010.

[29] R. Cazares, Optimización en el proceso de tintura y acabado de tejidos poliéster/lana con colorantes forosyn, Ibarra: Trabajo de Grado, Universidad Técnica del Norte, Ecuador, 2008.

[30] X. Weibin, H. Jinxin, C. Shuilin, C. Guoqiang and Taoz, "Modification of silk with aminated polyepichlorohydrin to improve dyeability with reactive dyes.," Coloration Technology, 2(123), 74-79, 2007.

[31] L. Martínez, H. Álvarez and S. Del Val, “Teñido de seda con colorantes naturales," 2009.

[32] A. K. R. Choudhury, S. Chanda, P. Pal and U. Das, "A preliminary study on dyeing of super wash wool-silk blends," Colourage, 59(6), 49-56, 2012.

[33] P. Saravanan and G. Chandramohan, "Dyeing of silk with ecofriendly natural dye obtained from barks of Ficus Religiosa," Universal Journal of Environmental Research and Technology, 1, 268-273, 2011.

[34] N. Rungruangkitkrai and R. Mongkholrattanasit, "Eco-Friendly of textiles dyeing and printing with natural dyes," in RMUTP International Conference: Textiles \& Fashion, Bangkok, 2012.

[35] M. Kumaresan, P. Palanisamy and P. Kumar, "Application of ecofriendly natural dye on silk using combina- tion of mordants," International Journal of Chemistry Research, 2(1), 11-14, 2011.

[36] S. Tepparin, P. Sae be, J. Suesat, S. Chumrum and W. Hongmeng, "Dyeing of cotton, Bombyx mori and eri silk fabrics with the natural dye extracted from tamarind seed," International Journal of Bioscience, Biochemistry and Bioinformatics, 2(3), 159-163, 2012.

[37] C. Wang, C. Xu, A. Tian, S. Fu and C. Wang, “Extraction of natural dyes from Alpinia blepharocalyx K. Schum. for dyeing of silk fabric," Coloration Technology, 129 (1), 1-7, 2012.

[38] L. Fuster, M. Mecklenburg, D. Yusá, S. Vicente and A. F. Batista dos Santos, "Effects of mordants on the mechanical behaviour of dyed silk fabrics: preliminary tests on cochineal dyestuffs.," Arché, 2, 115-120, 2007.

[39] N. Pruthi, G. Chawla and S. Yadav, "Dyeing of silk with barberry bark dye using mordant combination," Indian Journal of Natural Products and Resources, 7(1), 40-44, 2008.

[40] K. Prabhu and M. Teli, "Eco-Dyeing Using Tamarindus indica L. Seed Coat Tannin as a Natural Mordant for Textiles with Antibacterial Activity.," Journal of Saudi Chemical Society., 2011.

[41] R. Christie, Colour chemistry, Cambridge: The Royal Society of Chemistry, 2001.

[42] F. Reinoso, Diagnostico y análisis del proceso de lavado posterior a la tintura con colorantes reactivos por agotamiento sobre tejidos de punto de algodón $100 \%$ en la ciudad de Quito, Quito: Tesis de grado. Universidad Tecnológica Equinoccial. Ecuador, 2004.

[43] K. Uddin and S. Hossain, "A comparative study on silk dyeing with acid dye and reactive dye," International Journal of Engineering \& Technology, 10(6), 21-26, 2010.

[44] M. Hosseini, M. Montazer and R. Damerchely, "Enhancing dye-ability and antibacterial features of silk through pre-treatment with chitosan," Journal of Engineered Fibers and Fabrics, 8(3), 102-111, 2013.

[45] HUNSTMAN, "HUNSTMAN," [Online]. Available: http://www.huntsman.com. [Accessed Julio 2012].

[46] P. T.-F. Chong, "Colorimetry for textile applications," in Modern Textile Characterization Methods, New York, MARCEL DEKKER, INC, 1996, pp. 355-392.

[47] R. Hoban and R. Stone, "New gray scales simplify color assessments," Textile Chemist \& Colorist, 6(9), 38-43, 1974. 